\title{
Lexis
}

Journal in English Lexicology

Book reviews | 2007

\section{Riitta VÄLIMAA-BLUM, Cognitive Phonology in}

Construction Grammar. Analytic Tools for Students of

English

Mouton De Gruyter, 2009, 271 pages

Manuel Jobert

\section{CpenEdition}

Journals

Electronic version

URL: http://journals.openedition.org/lexis/1649

DOI: 10.4000/lexis.1649

ISSN: 1951-6215

Publisher

Université Jean Moulin - Lyon 3

Electronic reference

Manuel Jobert, «Riitta väLımaA-Blum, Cognitive Phonology in Construction Grammar. Analytic Tools for Students of English », Lexis [Online], Book reviews, Online since 20 December 2007, connection on 24 September 2020. URL : http://journals.openedition.org/lexis/1649 ; DOI : https://doi.org/10.4000/ lexis. 1649

This text was automatically generated on 24 September 2020

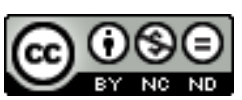

Lexis is licensed under a Creative Commons Attribution-NonCommercial-NoDerivatives 4.0 International License. 


\section{Riitta VÄLIMAA-BLUM, Cognitive} Phonology in Construction Grammar. Analytic Tools for Students of English

Mouton De Gruyter, 2009, 271 pages

Manuel Jobert

\section{REFERENCES}

Riitta Välimaa-Blum

Cognitive Phonology in Construction Grammar Analytic Tools for Students of English. Berlin; New York: Mouton de Gruyter, 2005. ISBN-13: 978-3-11-018686-4 pb, Prix : $29.53 €$, 271 pages

1 Riitta Välimaa-Blum's book covers the major aspects of phonetics and phonology: articulatory phonetics, sounds and meaning, alternation patterns, word stress and intonation.

2 Chapter 1 provides a brief and synthetic description of cognitive linguistics and construction grammar, underscoring the fact that their goals are somewhat similar. The purpose of cognitive phonology being to relate mental representations to what is actually found in utterances, the author distinguishes between three levels of representation:

- The morpheme level which contains the lexicon containing "all the non-automatic allomorphs and the word schema" (30)

- The phonemic or word level at which "morphological schemas and lexical stems create words through unification" (30)

- The phonetic or utterance level where "words are concatenated to form longer utterances" (30). Sandhi phenomena appear at this level. 
3 Chapter 2, devoted to articulatory phonetics, is clear and precise. The standpoint adopted is a traditional one. Its major merit is to present Southern British English and General American simultaneously, focusing on the more salient differences.

In chapter 3, the tension between ease of articulation and ease of perception is clearly analysed and the pronunciation of the plural morpheme /Iz/ is taken as an example. The distinction between hyper- and hypo-speech is then explained in detail. Riitta Välimaa-Blum insists on the fact that morphemes - not sounds - are learnt. The consequence is that "the mental representation of the lexicon would be expected to contain both predictable and non-predictable information about sounds in them". (55). The phoneme is defined as follows: "The phoneme is a prototype-centered, gradient class of phonetically similar sounds which all serve the same distinctive function" (57). The author concludes that in the minds of speakers, phonemes are stored within morphemes and therefore contain all the phonetic details. This explains why variability (between speakers or between accents) is not a problem as speakers recognize the target phoneme despite different allophonic realisations. The notions of minimal pairs and complementary distribution are then explained from a traditional perspective and the cognitive implications are presented. The author insists that the different phonetic contexts in which allophones occur are present at the so-called phonemic level of description and stored as such in the mental lexicon. The example of $/ 1 /$ is presented, giving the following representation:

\begin{tabular}{|l|l|l|l|}
\hline Phonemic level & $/ 1$ & $\sharp /$ & \\
\hline Phonetic level & {$[\ldots . .1]+[\Lambda]$} & {$[1] \#$} & \\
\hline & & {$[1][+$ consonantal $]$} & $(66)$ \\
\hline
\end{tabular}

5 Other examples are also provided, including nasality, in order to explain the hypotheses put forward. The same principle also accounts for free variation. In this chapter, the author alternates between traditional descriptions and more cognitively motivated arguments. This way of presenting information is indeed reassuring for phoneticians with little cognitive background but the cognitive added value appears quite thin at times. However, because of the number of examples examined and thanks to the clear and precise style, the points are clearly made. The summaries that conclude every chapter encapsulate the major points developed and are very useful. The first lines of the summary of chapter 3 are a good example:

I propose that the phoneme is an actual class of sounds, composed of its coallophones. These variant pronunciations are stored in the lexicon as exemplars in the morphemes, and they are fully specified for both their distinctive features and the predictable, sub-phonemic detail. The exemplars also probably correspond to generalizations in terms of procedural information vis-à-vis their typical phonetic contexts, thus transcending the symbolic units. (97)

6 Chapter 4, devoted to "alternation patterns", deals with the features that have to be stored in the mental lexicon of speakers in order to use words appropriately (semantically, syntactically and phonetically). The example given is that of the morpheme wife. The two forms /waIf/ and /waIv/* must be stored in the mental lexicon and the presence of the plural morpheme triggers the use of $/ /^{*}$. The choice of 
the allomorph /waIv/* is thus morphologically conditioned. This goes against the notion that the presence of $/ z$ / determines the use of /waIv/*, in which case, the choice of the allomorph would be phonologically conditioned. The author then discusses the case of irregular forms. The point made is that irregular forms are learnt alongside the regular forms and that they are all present in the mental lexicon. The same underlying principle applies to word formation as such: word formation is based on word schemas i.e. morphological rules. Several types of operations are at work. The author takes the example of articulate and posits that at least three allomorphs exist in the lexicon: /artikjolət/, /artikjoleIt/ and /artikjoleIJ/. When the verb is made into a process noun, the last schema is selected, giving, after suffixation, articulation. The same process is applied to the -ed morpheme, 's, -ity, the velar nasal, the prefix /Iy/ and its variant $/ \mathrm{I} K /$, sandhi phenomena, linking and so on. The point made is that word schemata (i.e. morphological rules) identify the allomorphs with which they combine and select them. Stress, it is claimed, is not included at the morphemic level unless it is irregular. In this chapter, the author claims that "prime minister tends to be pronounced /'praim mi'nistə/" (144) as a result of stress clash. Even if this stress pattern exits (though no statistical evidence is provided), it can in no way be regarded as the general pronunciation and the standard /,praIm 'mInIstə/ is more the norm than the exception (even in connected speech) although, it has to be admitted, a micropause often occurs to minimize the impact of the two successive stresses.

7 Chapter 5 is entirely devoted to word stress. The author starts with a precise presentation of the acoustic correlates of lexical stress. The scope covered is pretty comprehensive with a discussion of function words, separable and inseparable prefixes, weak and strong suffixes/endings and so on. To take an example of how word stress is envisaged, let's turn to page 178-179. It is posited that the sound shape of educate is

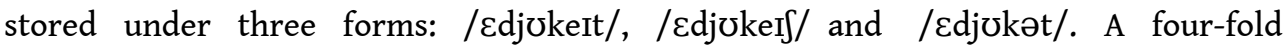
morphological schema is then applied: firstly, the suffix -ion is applied, secondly, a primary stress is placed on the preceding syllable, thirdly, the derived word is recognized as a noun, fourthly, the meaning is <action or condition> named by the verb, hence, education. 23 morphological schemata are presented. The notion of entrenchment is then explained before the author deals with compounds (very briefly) and stress-shift. Secondary stress is also accounted for. Throughout the book, the author makes a point of stressing the differences between the SPE-framework and her own. However, there are striking similarities between the morphological schemata presented by Riitta Välimaa-Blum and the rules of generative phonology. The differences are posited but could be discussed more thoroughly. The author indeed rejects the notion of an underlying form from which rules are applied. Morphological schemata do not work at the same level as SPE rules.

Chapter $\mathbf{6}$ is very short and deals with intonation and grammatical constructions. The basic information on the subject is there (broad/narrow focus, default contours etc.) but the presentation is too brief to be fruitfully commented upon.

Chapter 7 concludes this high speed trip into English phonology emphasising that derivation simply does not exist in phonology and that the morphemic, phonemic and phonetic levels are maximally identical. In other words, the author claims there is a continuum between morphology, phonology and syntax.

10 This book on English phonology is to be welcomed as cognitive linguistics usually ignores phonology. Pronunciations have indeed to be mentally represented. Riitta 
Välimaa-Blum builds on previous cognitive studies, not without challenging some of them (J.R Taylor 2002 for instance). In Cognitive Phonology in Construction Grammar, traditional phonetics is presented alongside more challenging though engaging discussions. What is troublesome, however, is the way the author remains extremely tentative in her formulations (eg. "We may now then assume ..." (178), "I would argue ..." (178), "we can assume ..." (179). The book is well referenced (apart from obvious omissions, Durand \& Laks 2002 or Laks 1996) but it is not always clear whether some of the hypotheses presented are based on neuro-linguistic evidence, on previous experiments or on intuitions. This is probably the weakest point of the book, which, of course, can be partly accounted for by the fact that this textbook is the first attempt to offer an almost comprehensive view of cognitive phonology. Some of the hypotheses presented will have to be confirmed, others will undoubtedly be challenged.

Having said that, the presentation of the phonetic facts, the pedagogical style as well as the number of issues tackled make Cognitive Phonology in Construction Grammar a good textbook for students of English phonology and/or cognitive linguistics. Proper guidance will nevertheless prove necessary to qualify some of the statements made and to place some arguments into a larger perspective.

\section{BIBLIOGRAPHY}

DURAND J \& LAKS B. Phonetics, Phonology and Cognition, Oxford, O.U.P. 2002.

LAKS B. Langage et Cognition : l'approche connexionniste, Paris, Hermes Sciences Publications, 1996.

TAYLOR J.R. Cognitive Grammar, Oxford, O.U.P. 2002.

\section{AUTHORS}

\section{MANUEL JOBERT}

Manuel Jobert, département d'anglais, Université Jean Moulin - Lyon 3. CREA - EA 370 Paris X Nanterre.

Manuel Jobert, agrégé d'anglais, est Maître de Conférences à l'Université Jean Moulin - Lyon 3 où il enseigne la stylistique et la phonétique. Il est l'auteur d'une thèse sur l'utilisation des traits paralinguistiques vocaux dans les romans d'Edith Wharton (2003). Ses recherches portent sur l'analyse du discours littéraire et sur les liens entre écriture et oralité. 